\title{
Temporal detection of caspase- 3 and -7 in bovine in vitro produced embryos of different developmental capacity
}

\author{
Leen Vandaele, Bart Mateusen, Dominiek G D Maes, Aart de Kruif and Ann Van Soom \\ Department of Reproduction, Obstetrics and Herd Health, Faculty of Veterinary Medicine, Ghent University, \\ Salisburylaan 133, B-9820 Merelbeke, Belgium
}

Correspondence should be addressed to L Vandaele; Email: leen.vandaele@ugent.be

\begin{abstract}
Embryo quality is most frequently evaluated at the blastocyst stage, although quality parameters further back along the developmental axis, such as early developmental kinetics or oocyte quality, can be equally valuable. Despite the fact that previous studies in bovine have linked oocyte diameter and early developmental kinetics with blastocyst formation and viability, their relation with the incidence of apoptosis during embryo development remains relatively unexplored. Therefore, we related noninvasive parameters of oocyte and embryo quality, such as embryo kinetics, embryo morphology, and oocyte diameter, to the incidence of apoptosis throughout embryo development using fluorescent detection of active caspase-3 and -7. First, bovine in vitro embryos were selected according to developmental kinetics and morphology at four set times during culture and subjected to fluorescent detection of active caspase-3 and -7. Caspase activity was significantly higher in slow developing embryos in comparison with fast cleavers $(P<0.05)$, but was not related to embryo morphology. Second, bovine oocytes were divided into three groups on the basis of oocyte diameter and the resulting embryos were used for staining at the same four set times. Caspase activity was significantly higher in embryos derived from growing oocytes compared with those of fully grown oocytes at 45,80 , and 117 hours post-insemination (hpi; $P<0.05$ ), but not at $168 \mathrm{hpi}$.
\end{abstract}

Reproduction (2007) 133 709-718

\section{Introduction}

Evaluation and prediction of in vitro embryo quality has become a key issue both for commercial embryo transfer and for research purposes (Maddox-Hyttel et al. 2003). Selection of embryos of superior morphology remains the most practical and clinically useful approach in bovine and human embryo transfer (Overström 1996, Alikani et al. 2002). Superior embryo morphology is mainly characterized by evenly sized blastomeres and the absence of fragmentation (Lindner \& Wright 1983) and is most frequently evaluated at the blastocyst stage (Bavister 1995). In human and porcine embryos, embryonic fragmentation is linked with apoptosis (Jurisicova et al. 1996, Mateusen et al. 2005); however, in vitro produced bovine morulae show no clear correlation between fragmentation and apoptosis, particularly in those embryos where fragments makeup $<50 \%$ of the total embryo volume (Van Soom et al. 2003). Further work is required to determine the underlying mechanisms surrounding embryonic fragmentation.

Besides frequently used morphological evaluation of blastocyst superiority, other quality parameters further back along the developmental axis, such as morula compaction, early developmental kinetics, or oocyte quality, can be equally valuable and are often neglected. Although previous studies in bovine have linked oocyte diameter and early developmental kinetics with blastocyst formation and viability (Van Soom et al. 1992, Grisart et al. 1994, Fair et al. 1995, Otoi et al. 1997), their relation with the incidence of apoptosis during embryo development remains unexplored. Suboptimal culture conditions undoubtedly contribute to embryonic apoptosis, but the intrinsic quality of the oocyte and the embryo may also be a causative factor. It is generally accepted that the oocyte is in control of early embryogenesis: during early cleavage stages, embryonic development is supported by maternal mRNAs and proteins synthesized and stored during oocyte growth (Fair et al. 1995). Inadequate provision of maternal products to the early embryo may lead to delayed embryo development or even embryonic demise (Jurisicova \& Acton 2004). Transcripts of genes of Bcl-2 family members are present at different levels in human oocytes, resulting in a different balance in expression of pro- and anti-apoptotic genes, which may shift the 
oocyte's developmental potential in the direction of either cell death or cell survival (Jurisicova \& Acton 2004). We have recently shown that maternal transcripts of caspase- 3 and -7 , which play an important role in the caspase cascade of apoptosis, are also expressed in 40 and $30 \%$ of bovine oocytes respectively, but we could not demonstrate the presence of active caspases in fresh oocytes (Yuan et al. 2005). Since the influence of oocyte quality may only become obvious after oocyte fertilization or during the transition to embryonic control (Jurisicova \& Acton 2004), we speculated that oocyte quality and consequently embryo quality in terms of early development and morphology could both be related to apoptosis.

In order to prevent false-positive results in some cases of necrosis, it has been postulated that reliable information on the level of apoptosis can rather be gained by the detection of specific proteins from the apoptotic cascade system such as active caspases than by TUNEL or Annexin V staining (Grasl-Kraupp et al. 1995, Levy et al. 1998, Martinez et al. 2002). At least 14 different caspases were initially detected at the level of mRNA using RT-PCR, six of which were present in cattle (Shi 2002, Yuan et al. 2004). Because caspase-3 and -7 are both executioners of apoptosis and because especially caspase-3 (Earnshaw et al. 1999) is involved in both the receptor-mediated and the intrinsic pathway of apoptosis, immunofluorescent staining of active caspase- 3 and -7 was chosen to determine the incidence of apoptosis in embryos.

Therefore, the aim of the present study was to relate non-invasive parameters of oocyte and embryo quality, such as embryo kinetics, embryo morphology, and oocyte diameter, with the incidence of apoptosis throughout embryo development using fluorescent detection of active caspase- 3 and -7 .

\section{Materials and Methods}

\section{Media and reagents}

Basal medium eagle amino acids, minimal essential medium non-essential amino acids $(100 \times)$, TCM-199medium, and gentamycin were obtained from GIBCOBRL Life Technologies (Merelbeke, Belgium). Fetal calf serum (FCS) was purchased from Biochrom AG (Berlin, Germany), CaspaTag Pan-Caspase in situ Assay kits (Fluorescein) were purchased from Chemicon Belgium (Leuven, Belgium), and all other components were purchased from Sigma. All media were filtersterilized $(0.22 \mu \mathrm{m}$ Millipore Co. New Bedford, MA, USA) prior to use.

\section{In vitro production of embryos}

Bovine embryos were produced by routine in vitro methods (Vandaele et al. 2006). Briefly, bovine ovaries were collected at the abattoir and processed within $2 \mathrm{~h}$. The ovaries were washed thrice in warm physiological saline supplemented with kanamycin $(25 \mathrm{mg} / \mathrm{ml}$, GIBCO-BRL Life Technologies, Merelbeke, Belgium). The oocytes were aspirated from follicles between 4 and $8 \mathrm{~mm}$ in diameter and cultured in groups of 100 in $500 \mu \mathrm{l}$ modified bicarbonate buffered TCM199 supplemented with $20 \%$ heat-inactivated FCS (Biochrom AG, Berlin, Germany) for $20-24 \mathrm{~h}$ at $38.5{ }^{\circ} \mathrm{C}$ in $5 \% \mathrm{CO}_{2}$ in air. Frozen-thawed bovine semen was separated over a Percoll gradient (45 and 90\%; Pharmacia, Uppsala, Sweden) and washed. The final sperm concentration of $1 \times 10^{6} \mathrm{sp} / \mathrm{ml}$ was adjusted in IVF-TALP, consisting of bicarbonate buffered Tyrode solution, supplemented with BSA $(6 \mathrm{mg} / \mathrm{ml})$ and heparin $(25 \mu \mathrm{g} / \mathrm{ml})$. The matured oocytes were washed in $500 \mu \mathrm{IVF}-\mathrm{TALP}$ and incubated with sperm. After 20-24 h incubation, the presumed zygotes were vortexed to remove excess sperm and cumulus cells. The washed zygotes were transferred to synthetic oviduct fluid supplemented with amino acids and FCS (SOFaa $+5 \%$ FCS) medium and were cultured in $50 \mu \mathrm{l}$ droplets under mineral oil in groups of 25 in $5 \%$ $\mathrm{CO}_{2}, 5 \% \mathrm{O}_{2}$, and $90 \% \mathrm{~N}_{2}$.

\section{Cumulus cell culture}

For the evaluation of the caspase staining, a cumulus cell monolayer was established for each replicate. Each well of a four-well culture dish contained a cell culture insert and was pre-incubated with $400 \mu \mathrm{l} \mathrm{FCS} \mathrm{for} 1 \mathrm{~h}$ at $38.5^{\circ} \mathrm{C}$ in order to stimulate the attachment of the cumulus cells onto the insert. After vortexing of the presumed zygotes, the cumulus cells were isolated and centrifuged at $750 \mathrm{~g}$ for $10 \mathrm{~min}$. Following the removal of the supernatant, the pellet was resuspended in $2 \mathrm{ml}$ modified culture medium (bicarbonate buffered TCM 199, 10\% FCS, and 0.1\% gentamycin) and each well was filled with $500 \mu \mathrm{l}$ cumulus cell suspension and allowed to settle. Culture took place at $38.5^{\circ} \mathrm{C}$ in $5 \% \mathrm{CO}_{2}$ in air and the medium was replaced twice after 72 and $144 \mathrm{~h}$ of culture, at which time the cumulus cells had reached confluence.

\section{Evaluation of apoptosis by means of caspase-3 and -7 staining}

Caspase- 3 and -7 were stained by means of fluorochrome labeled inhibitor of caspase (FLICA) using the CaspaTag Pan-Caspase in situ Assay kit, Fluorescein (Chemicon). The FLICA probe, a carboxyfluoresceinlabeled fluoromethyl ketone peptide inhibitor of caspase (FAM-DEVD-FMK) was designed to specifically bind caspase-3 by incorporating four-amino acid peptide moiety. After entering the cell, the non-cytotoxic probe will covalently bind not only to caspase-3, but also to caspase-7. The FLICA staining solution was diluted 150 times and centrifuged for 3 min at $8450 \mathrm{~g}$ immediately 
before use. The washing buffer from the staining kit was diluted ten times in distilled water and stored at $-20{ }^{\circ} \mathrm{C}$ for a maximum of 2 weeks.

The cumulus cell culture was stained simultaneously with the embryos selected at 168 hours post-insemination (hpi). During the staining procedure, light exposure was kept to a minimum. Positive controls were incubated in $0.5 \mu \mathrm{M}$ staurosporine for $24 \mathrm{~h}$ before staining for embryos and $12 \mathrm{~h}$ before staining for two positive wells of cumulus cell monolayers. Immediately after selection and washing in polyvinyl pyrrolidone (PVP, $0.1 \%$ in PBS) solution, positive controls (embryos and one well of the cumulus cell monolayer) and test embryos were incubated in FLICA staining solution $(35 \mu \mathrm{l}$ droplets for embryos and $300 \mu \mathrm{l}$ for cumulus monolayers) for $1 \mathrm{~h}$ at $38.5{ }^{\circ} \mathrm{C}$ in $5 \% \mathrm{CO}_{2}$ in air. Meanwhile, negative controls (embryos and one well of the cumulus cell monolayer) were incubated in PVP solution. Then all embryos and cell monolayers were washed in wash buffer for $5 \mathrm{~min}$ at RT and subsequently fixed in the $300 \mu$ fixative included in the staining kit in a four-well dish for $15 \mathrm{~min}$ at RT in darkness. After fixation, all the embryos and cumulus cells were permeabilized with $0.5 \%$ Triton X-100 in PBS for 15 min at RT and subsequently washed twice in PVP solution for $2 \mathrm{~min}$. In order to prevent RNA staining by propidium iodide $(\mathrm{PI})$, the embryos and cumulus cells were incubated in RNase A ( $50 \mu \mathrm{g} / \mathrm{ml}$ in PBS) for $1 \mathrm{~h}$ at $37^{\circ} \mathrm{C}$. The nuclei were then counterstained with $0.5 \% \mathrm{PI}$ in PVP in droplets for $15 \mathrm{~min}$. After a quick wash in PVP, the embryos were mounted in glycerol with 1,4-diazabicyclo (2.2.2) octane $(25 \mathrm{mg} / \mathrm{ml}$; Acros, Ghent, Belgium) on slides with vaseline bridges. Similarly, the inserts with cumulus cells were removed and mounted in a small droplet of glycerol with 1,4-diazabicyclo (2.2.2) octane $(25 \mathrm{mg} / \mathrm{ml}$; Acros, Ghent, Belgium).

\section{Experimental design}

Experiment 1: detection of caspase-3 and -7 during early embryo development in relation to developmental kinetics and embryo morphology

A total of 2640 immature bovine oocytes were matured, fertilized, and cultured in vitro (four replicates). Each replicate consisted of 110 positive control embryos, 110 control embryos, and 440 test embryos. The cleavage rate was determined at $45 \mathrm{hpi}$ for all embryos, except for the positive controls. The test embryos (110 at 45, 80, 117 , and 168 hpi respectively) were allocated to four groups according to their developmental kinetics and morphology (Fig. 1). The time points and criteria for the selection of fast or slow developing embryos were determined on the basis of previous studies in similar culture conditions (Dinnyés et al. 1999, Lonergan et al. 1999, Yoshioka et al. 2000, Lequarré et al. 2003) and verified in a preliminary experiment (data not shown).

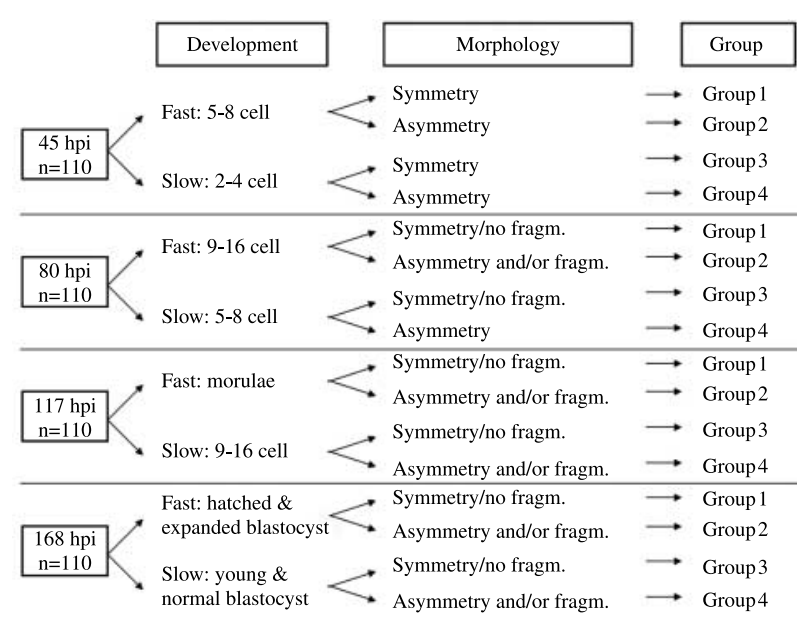

Figure 1 Allocation of embryos at 45, 80, 117, and $168 \mathrm{hpi}$ in four different groups according to their developmental kinetics and morphology (fragm, fragmentation).

As far as the developmental kinetics were concerned, embryos that were lagging one cell cycle behind at each time point were considered impaired (slow developers). Embryos of poor morphology were asymmetrical or fragmented as judged by stereomicroscopical evaluation (wild stereomicroscope with total magnification $75 \times$ ). Embryos were judged to have a good morphology when they were symmetrical without any fragmentation. All selected embryos were washed four times in PVP solution before caspase staining. The apoptotic cell ratio (ACR) was compared at all time points between groups. Finally, the blastocyst yield of the control embryos was evaluated at $168 \mathrm{hpi}$.

Experiment 2: temporal expression of caspase-3 and -7 in embryos originating from oocytes with different diameters

A total of 3300 immature bovine oocytes were matured, fertilized, and cultured in vitro (five replicates). Each replicate consisted of 110 positive control embryos, 110 control embryos, and 440 test embryos. The diameter of the test zygotes (cytoplasm without zona) was measured at $24 \mathrm{hpi}$ (after vortexing) using a stereomicroscope, magnification $75 \times$, equipped with an eyepiece with a micrometer cross. On the basis of these findings, the test zygotes were divided in three groups: small $(<110 \mu \mathrm{m})$, medium $(110-120 \mu \mathrm{m})$, and large oocytes $(>120 \mu \mathrm{m})$. The oocyte and zygote diameters are considered to remain the same throughout maturation and fertilization. The cleavage rate was determined at $45 \mathrm{hpi}$ for all embryos, except for the positive controls. At each of the four time points $(45,80,117$, and $168 \mathrm{hpi})$, embryos were selected from each of the three diameter groups on the basis of their development. In this way, at each time point, one-fourth of the embryos in each diameter group (approximately 25 small, 50 medium, and 25 large 
oocytes) were evaluated for selection. From each of the three diameter groups, 2- to 8-cell embryos were selected at $45 \mathrm{hpi}, 5$ - to 16 -cell embryos at $80 \mathrm{hpi}, 9$ to 16 -cell embryos and morulae at $117 \mathrm{hpi}$, and at 168 hpi blastocysts were counted and recovered. The division of selected embryos in each diameter group in analogy with the first experiment (in four groups according to developmental kinetics and morphology) would have led to 12 groups in total and was therefore practically not possible. After four washes in PVP solution, all selected embryos were immediately stained for caspase-3 and -7 in three oocyte diameter groups. The cleavage and blastocyst rate were compared between groups and with the control group. Furthermore, the total cell number and the ACR were compared over each time point between groups.

\section{Statistical analysis}

In the first experiment, mixed model univariate analyses of variance were performed with group as fixed factor and replicate as random factor. Replicate was included as a random variable. The analyses were repeated at each time point separately, namely 45, 80, 117 , and 168 hpi. Post hoc pairwise comparisons between the groups were made using Scheffe's tests.

In the second experiment, mixed model univariate analyses of variance with group as fixed factor and replicate as random factor were used to evaluate total cell number and ACR at each time point $(45,80,117$, and $168 \mathrm{hpi}$ ). Post hoc pairwise comparisons between the groups were made using Scheffe's tests. The percentage of cleaved embryos (at $45 \mathrm{hpi}$ ) in all test droplets was investigated using mixed model analyses of variance with group as fixed and replicate as random factor. Because of the low number of remaining droplets at $168 \mathrm{hpi}$, logistic regression with blastocyst yield as dependent variable and oocyte diameter as independent variable including the effect of replicate was used to compare the blastocyst development in the three groups.

For all mixed model analyses, the assumptions of the models, namely normal distribution of data and homogeneity of variances between the groups, were checked. Differences were considered to be statistically significant at the $5 \%$ level (two-sided). Statistical analyses were performed using SPSS version 12.0.

\section{Results}

\section{Experiment 1}

Total cleavage rates at $45 \mathrm{hpi}$ and blastocyst yield at 168 hpi were 60.5 and $26.9 \%$ respectively. Active caspase- 3 and -7 could be detected at the earliest time points and thus from the two-cell stage onwards. The mean ACR was significantly lower in embryos with fast development and normal morphology at all time points and in embryos with fast development and poor morphology at 45 and 117 hpi $(P<0.01$; Fig. 2). A significantly higher ACR was found in slow developing embryos, in comparison with fast cleaving embryos $(P<0.01$; Fig. 3). Although caspase activity was frequently observed in fragments, the differences in caspase activity between embryos with good and poor morphology were not significant $(25.5 \pm 1.3 \%$ for good morphology and $28.8 \pm 2.0 \%$ for bad morphology), indicating that asymmetrical cleavage or fragmentation is not related to early signs of apoptosis. Although the incubation of positive control cumulus cells with staurosporine inhibited monolayer formation, control staining of negative and positive cumulus cells was satisfactory for each replicate and proved the reliability of the caspase staining (Fig. 4).

\section{Experiment 2}

Cleavage rates at $45 \mathrm{hpi}$ and blastocyst yield at $168 \mathrm{hpi}$ in control embryos were 58.5 and $22.3 \%$ respectively

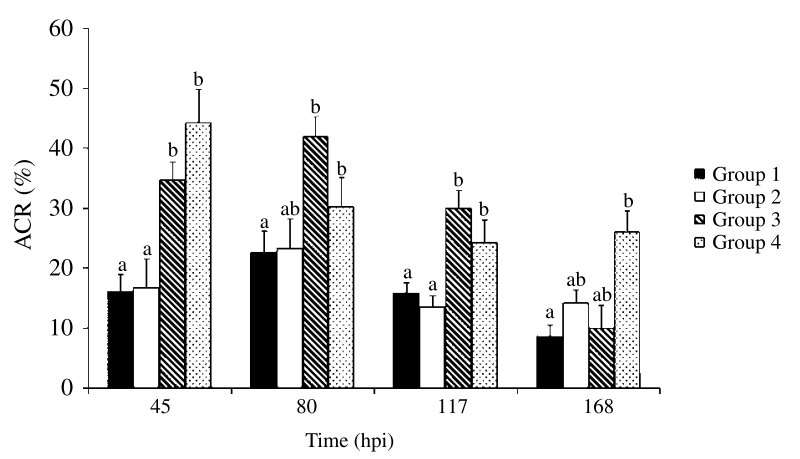

Figure 2 Mean apoptotic cell ratio (ACR) and S.E.M. at 45, 80, 117, and $168 \mathrm{hpi}$ in group 1 (embryos with fast development and good morphology), group 2 (embryos with fast development and poor morphology), group 3 (embryos with slow development and good morphology), and group 4 (embryos with slow development and poor morphology). ${ }^{a, b}$ Bars with different superscript differ within each time point $(P<0.01)$.

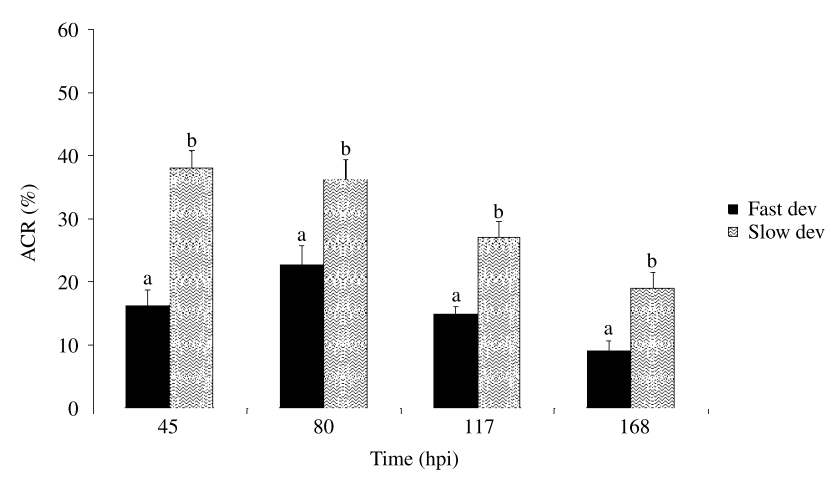

Figure 3 Mean apoptotic cell ratio (ACR) and standard error of the mean at $45,80,117$, and $168 \mathrm{hpi}$ in fast (fast dev) and slowly developing (slow dev) embryos. ${ }^{a, b}$ Bars with different superscript differ within each time point $(P<0.01)$. 

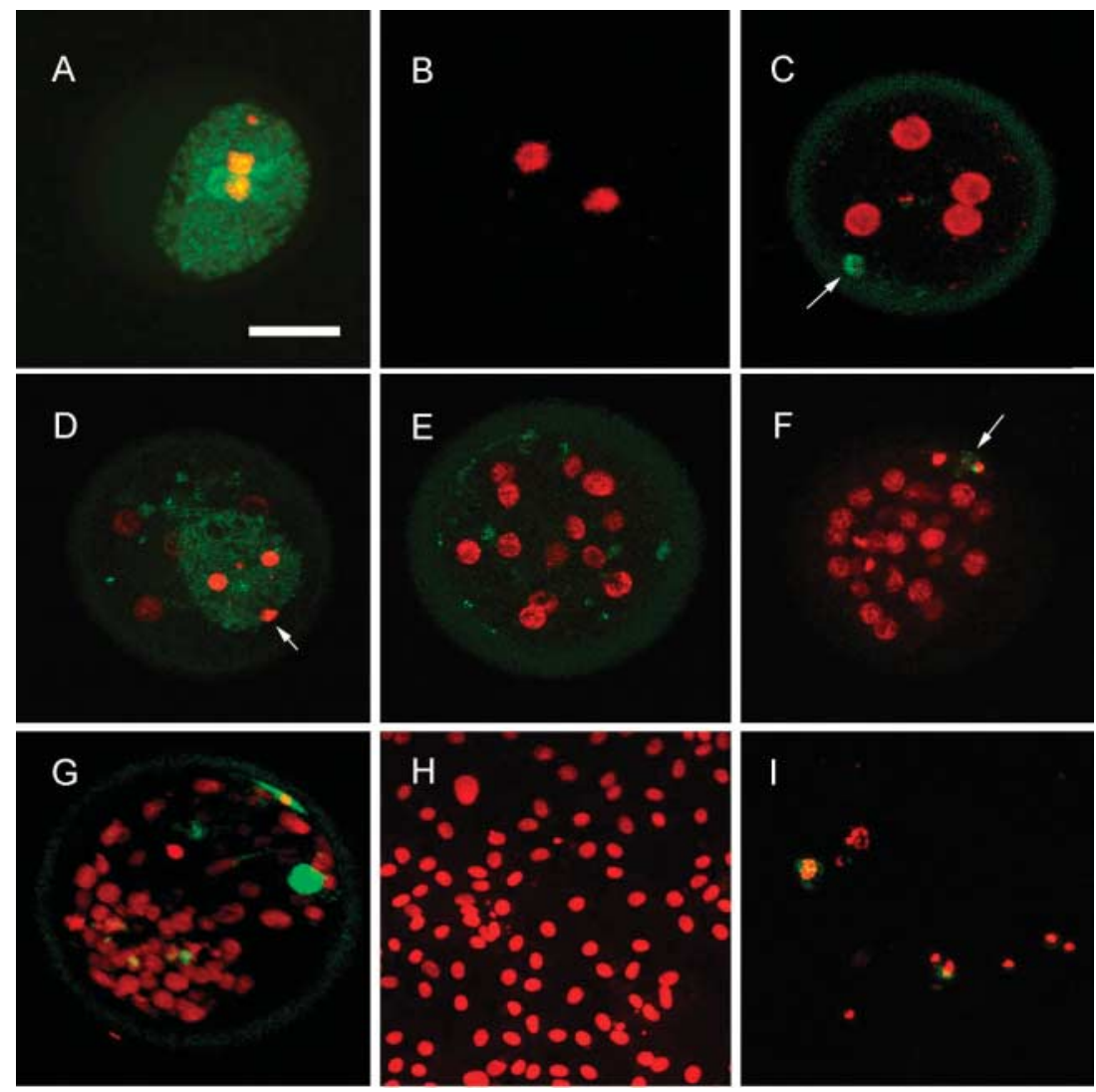

Figure 4 Active caspase- 3 and -7 staining of embryos at different developmental stages and of cumulus cell cultures (bar $=50.00 \mu \mathrm{m}$ ).

(A) Positive control two-cell embryo after staurosporine induction (caspase-positive cytoplasm is green, propidium iodide-positive nuclei are red). (B) Negative control two-cell embryo (no caspase detection in cytoplasm). (C) Two- to four-cell embryo with one positive area in cytoplasm (arrow). (D) Five- to eight-cell embryo with clear positive cytoplasm and condensed apoptotic nuclei in three cells (arrow). (E) Nine- to sixteen-cell stage embryo with several caspase-positive cells (green dots in cytoplasm). (F) Morula with one apoptotic cell (arrow). (G) Expanded blastocyst with several caspase-positive cells (green areas in cytoplasm). (H) Cumulus monolayer: negative control. I. Cumulus culture-positive control:

staurosporine induction overnight inhibited monolayer formation, but all cumulus cells are caspase positive (green area around PI-stained nuclei).

(Table 1). The cleavage rate was significantly lower in embryos originating from small oocytes in comparison with embryos from the medium or large group $(P<0.05$; Table 1). Oocyte diameter significantly affected the blastocyst rate at $7 \mathrm{dpi}(P<0.05)$ and medium and large oocytes developed significantly better to the blastocyst stages in comparison with small oocytes (Table 1). The total cell number of the embryos was significantly different between oocyte diameter groups at 45 and 80 hpi $(P<0.05)$, but not at 117 and $168 \mathrm{hpi}$ $(P>0.05)$. The pairwise comparisons at $45 \mathrm{hpi}$ indicated a significantly lower cell number in 2- to 8-cell embryos of the small group in comparison with the medium and large group $(P<0.05 ;$ Table 2$)$. At $80 \mathrm{hpi}$, a significantly higher total cell number was found in the large oocyte group in comparison with the small oocyte group $(P<0.05$; Table 2). The ACR showed a significant difference between groups at 45, 80, and $117 \mathrm{hpi}$ $(P<0.05)$, but not at 168 hpi $(P=0.06)$. Therefore, pairwise comparisons were only performed for the first three time points (Fig. 5). The embryos derived from oocytes with a small diameter had a significantly higher average ACR than embryos derived from large oocytes at 45, 80, and 117 hpi (Fig. 5).

Table 1 Number of droplets and number of embryos evaluated for cleavage rate and blastocyst determination respectively, and cleavage and blastocyst rate (mean \pm S.E.M.) in control embryos and embryos originating from small, medium, and large oocytes (experiment 2).

\begin{tabular}{|c|c|c|c|c|}
\hline & $\begin{array}{l}\text { Number of droplets } \\
\text { evaluated at } 45 \text { hpi }\end{array}$ & $\begin{array}{c}\text { Cleavage rate } \\
(\text { mean } \pm \text { S.E.M.; \%) }\end{array}$ & $\begin{array}{l}\text { Number of embryos } \\
\text { evaluated at } 168 \mathrm{hpi}\end{array}$ & $\begin{array}{c}\text { Blastocyst rate } \\
(\text { mean } \pm \text { S.E.M.; \%) }\end{array}$ \\
\hline Control group & 20 & $58.5 \pm 0.6$ & 485 & $22.6 \pm 0.4$ \\
\hline Small oocytes $(<110 \mu \mathrm{m})$ & 20 & $51.5 \pm 0.5^{*}$ & 141 & $9.2 \pm 1.9^{*}$ \\
\hline Medium oocytes (110-120 $\mu \mathrm{m})$ & 40 & $61.6 \pm 0.3^{+}$ & 300 & $18.3 \pm 1.0^{\dagger}$ \\
\hline Large oocytes $(>120 \mu \mathrm{m})$ & 20 & $67.0 \pm 0.5^{+}$ & 128 & $21.9 \pm 1.9^{\dagger}$ \\
\hline
\end{tabular}

\footnotetext{
${ }^{*}{ }^{\dagger}$ Values with different superscripts within the same column differ significantly $(P<0.05)$.
} 
Table 2 Total cell number (mean \pm S.E.M.) after caspase staining in embryos originating from small, medium, and large oocytes at 45, 80, 117, and 168 hpi with the number of evaluated embryos between brackets.

\begin{tabular}{lllll}
\hline & \multicolumn{1}{c}{$\mathbf{4 5} \mathbf{~ h p i}$} & \multicolumn{1}{c}{$\mathbf{8 0} \mathbf{~ h p i}$} & $\mathbf{1 1 7} \mathbf{~ h p i}$ & $\mathbf{1 6 8} \mathbf{~ h p i}$ \\
\hline Small oocytes $(<110 \mu \mathrm{m})$ & $3.9 \pm 0.2^{*}(n=41)$ & $7.3 \pm 0.3^{*}(n=24)$ & $18.3 \pm 1.4^{*}(n=21)$ & $90.7 \pm 9.5^{*}(n=7)$ \\
Medium oocytes $(110-120 \mu \mathrm{m})$ & $4.4 \pm 0.2^{*}(n=82)$ & $8.3 \pm 0.2^{*}(n=95)$ & $19.3 \pm 0.9^{*}(n=65)$ & $95.3 \pm 4.4^{*}(n=36)$ \\
Large oocytes $(>120 \mu \mathrm{m})$ & $5.2 \pm 0.3^{+}(n=54)$ & $9.4 \pm 0.6^{+}(n=36)$ & $21.1 \pm 1.8^{*}(n=34)$ & $99.3 \pm 5.3^{*}(n=20)$ \\
\hline
\end{tabular}

${ }^{*}{ }^{\dagger}$ Values with different superscripts within the same column differ significantly $(P<0.05)$.

\section{Discussion}

To our knowledge, the present study is the first one to use immunofluorescent detection of active caspases as an apoptotic marker during preimplantation development in bovine embryos. It also clearly demonstrated that active caspases can be detected from the two-cell stage in bovine IVF embryos. Moreover, a higher incidence of caspase-positive cells was evident in slow developing embryos at different time points during preimplantation development. Secondly, apoptosis was prominently influenced by oocyte quality until the morula stage, since cleaving embryos originating from small oocytes expressed a higher level of caspase activity.

The first appearance of apoptosis is species dependent and has been observed in bovine in vitro embryos to occur around the eight-cell stage, i.e. at the time of embryonic genome activation after TUNEL or TUNEL in combination with the evaluation of nuclear morphology (Byrne et al. 1999, Matwee et al. 2000, Gjørret et al. 2003). Since TUNEL only detects later stages of apoptosis, it may well be that earlier stages of apoptosis are already present in 2- to 8-cell embryos (Collins et al. 1997). The induction of DNA fragmentation with staurosporine throughout bovine embryo development (Matwee et al. 2000) and the detection of mRNA transcripts of caspase- 2 and -3 in all stages of human preimplantation embryos (Jurisicova et al. 2003) suggest that the full apoptotic machinery is already present in early cleavage embryos. The fluorescent detection of active caspases as early as the two-cell stage in our study has confirmed this possibility. Some of the two-cell embryos which stained positive for caspases and belonged to the slow developing group may have been in developmental arrest, which is in accordance with the previous studies where apoptosis has been demonstrated in arrested two- to four-cell human and pig embryos (Spanos et al. 2002, Mateusen et al. 2005). Notwithstanding the presence of the full apoptotic machinery in normal developing early stage embryos, in humans, caspase could only be detected from the compacted morula stage onwards (Spanos et al. 2002). A family of proteins called inhibitors of apoptosis proteins (IAPs) could play a pioneering role in this respect by binding directly to and inhibiting active caspases (Deveraux \& Reed 1999, Goyal 2001, Spanos et al. 2002). In this respect, it could be interesting to focus on immunofluorescent or other detection methods of IAPs in early arrested and non-arrested embryos.

The best known pathways of apoptosis, i.e. the mitochondrial and the receptor-mediated pathways, terminate with the activation of executioner caspases, which mediate the proteolytic cleavage of many proteins, leading to the typical apoptotic morphological features (Thornberry \& Lazebnik 1998). Mitochondrialmediated apoptosis results in the activation of caspase- 3 and -6 by initiator caspase- 9 , while initiator caspase- 8 and -10 activate executioner caspase- 3 and -7 in the receptor-mediated apoptotic pathway. Interestingly, recent research has discovered a third pathway of apoptosis in which endonuclease G, released from mitochondria and translocated to the nucleus, can fragmentize DNA independently of active caspases (Li et al. 2001). Nevertheless, the importance of caspases in the apoptotic mechanism cannot be neglected, since in several species, such as human, mouse, and rat, detection of caspase mRNAs and/or active caspase proteins has been associated with apoptosis during embryo development, mostly in a stage-specific manner (Exley et al. 1999, Hinck et al. 2001, Spanos et al. 2002, Jurisicova et al. 2003, Metcalfe et al. 2004). From the results of both our experiments, it was obvious that the percentage of caspase-positive cells declined in advanced developmental stages. Embryos with very high level of expression of active caspases were probably going into developmental arrest and were therefore no longer selected at the next time point. In this way, caspase activity is not per se negative, because it is

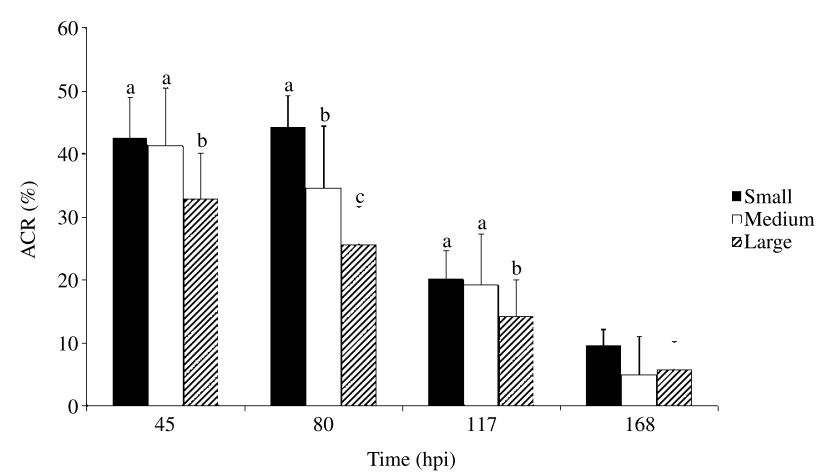

Figure 5 Mean apoptotic cell ratio (ACR) and standard error of the mean at $45,80,117$, and $168 \mathrm{hpi}$ in embryos originating from small, medium, and large oocytes. ${ }^{a, b, c}$ Bars with different superscript differ within each time point $(P<0.01)$. 
selecting against inferior embryos which are going into demise. In addition, it has been suggested that within embryos, activation of caspase can also occur through a non-apoptotic mechanism and may have a constructive role, rather than a destructive role in isolating fragments from healthy blastomeres (Martinez et al. 2002).

At each time point in the first experiment, symmetry and absence of fragmentation were used as morphological criteria, since both have been related to poor bovine embryo quality, lower pregnancy and implantation rates in cattle (Lindner \& Wright 1983), and higher incidence of apoptosis in pigs (Mateusen et al. 2005). Although abnormal morphology has been clearly associated with a higher apoptotic index and caspase expression in humans (Hardy et al. 1989, Martinez et al. 2002), and although fragmentation in humans can be associated with an expression of proapoptotic genes (Jurisicova et al. 2003), abnormal morphology during embryo development could not be related to higher caspase activity in our study. In similarity with the results of Martinez et al. (2002) in humans, we also observed a higher incidence of caspase activity in fragments (data not shown), despite the fact that the proportion of caspase activity did not differ between embryos of good and poor morphology. In agreement with our findings, neither Antczak \& Van Blerkom (1999) nor Wells et al. (2005) could find an association between fragmentation and apoptosis, a fact which they attributed to the diversity of mechanisms that can lead to fragmentation. Secondly, some researchers believe that embryo fragments are apoptotic bodies (Hardy 1999). Therefore, activation of caspases and fragmentation might not be correlated because apoptotic bodies are endpoints of apoptosis, whereas caspase activity occurs much earlier in the pathway. Thirdly, pattern and grade of fragmentation, which have not been evaluated in our study, may be responsible for different results, because minor fragmentation (below 15\%) seems to have no effect on subsequent development in pigs (Mateusen et al. 2005). Finally, the impact of asymmetry on embryo quality could be discussed, since it frequently disappears during in vitro pig embryo development (Mateusen et al. 2005). Further research aimed at clarifying the causes and mechanisms of fragmentation will probably help to explain the lack of correlation between embryo morphology and apoptosis in our study.

In contrast to the fact that morphological quality was not related to apoptosis, the first experiment clearly showed that embryos with slow development (meaning embryos that were lagging one cell cycle behind) had a higher incidence of apoptosis. Fast cleaving bovine embryos have an altered gene expression (Lonergan et al. 2000, Ward et al. 2001, Fair et al. 2004, Gutiérrez-Adán et al. 2004, Dode et al. 2006) or altered polyadenylation status of several developmentally important gene transcripts (Pocar et al. 2001, Brevini-Gandolfi et al. 2002) and a higher chance of reaching advanced developmental stages in comparison with late cleaving embryos (Van Soom et al. 1992, Dinnyés et al. 1999, Lonergan et al. 1999, Lequarré et al. 2003, Favetta et al. 2004, Gutiérrez-Adán et al. 2004). Studies investigating the effect of developmental kinetics on the incidence of apoptosis during preimplantation embryo development in bovine are scarce. Previous research in our department (Vandaele et al. 2006) showed that fast cleaving embryos generated blastocysts with a significantly lower ACR compared with slow cleaving embryos. Whether this could totally be attributed to cytoplasmic quality or whether a cooperative effect between the embryos was more important could not be deduced from this study (Vandaele et al. 2006). The first experiment was aimed at extending our knowledge about the importance of developmental kinetics in the incidence of apoptosis. It is our hypothesis that fast cleavers contain all the necessary gene products and proteins to support further development without any problems, whereas a lack of some gene products and proteins in slow cleavers could be related to a higher chance to go into developmental arrest or apoptosis. Many gene products such as histones $2 \mathrm{~A}$ and $3 \mathrm{~A}, \mathrm{YEAF}$, cathepsin B, and chaperonines TCP1, which are involved in genome regulation and transcription, protein turn-over, cell metabolism, and cytoskeletal organization, are expressed at higher levels in fast cleavers in comparison with slow cleavers (Kanka 2003, Fair et al. 2004, Vigneault et al. 2004, Dode et al. 2006). More importantly, we hypothesized that fast cleaving embryos may have a better cellular defense against oxidative stress, as was demonstrated by the higher expression of IDH and RAD50 (Dode et al. 2006). Both genes are involved in the stress protection of embryos, since $\mathrm{IDH}$, a NADP+-dependent isocytrate dehydrogenase modulates oxidative damage and RAD50 is involved in the DNA double-strand break repair (Lee et al. 2002, Huang \& Dynan 2002). Besides the lower expression level of some specific genes, gradual degradation of maternal mRNA (Dode et al. 2006) or lack of essential survival and growth factors and cytokines released by maternal cells (Brison \& Schultz 1997, Hardy 1999, Spanos et al. 2000, Sjöblom et al. 2005) can also be related to lower developmental competence and/or higher incidence of apoptosis in late cleaving embryos.

In the second experiment, the importance of oocyte quality in the induction of apoptosis in bovine in vitro embryos was further investigated at different time points during preimplantation development. The level of cytoplasmic maturation has been proposed as the common causative factor in the positive correlation between oocyte quality parameters (oocyte diameter, follicle size, morphology of cumulus-oocyte complex, composition of follicular fluid, and morphology of the ovary) and improved developmental competence (Lonergan et al. 1994, Arlotto et al. 1996). Our results not only confirmed the higher developmental fitness of 
large oocytes in terms of cleavage and blastocyst rate, but also pointed out that embryos originating from large oocytes had significantly higher cell numbers and lower percentage of caspase-positive cells at 45 and $80 \mathrm{hpi}$. At $168 \mathrm{hpi}$ (blastocyst stage), no effect of oocyte diameter on blastocyst quality in terms of cell number and/or caspase activity could be detected. These results showed, in agreement with previous studies, that the effect of oocyte quality on embryo quality is restricted during later developmental stages and ends before the blastocyst stage (Brevini-Gandolfi \& Gandolfi 2001). This could easily be explained by the fact that an embryo fully depends on maternal cytoplasm until the maternal embryonic genome transition takes place from the 8- to 16-cell stage, since no (or very few) mRNAs are formed until then (Rodriguez \& Farin 2004). Fully mature cytoplasm of the oocyte provides the embryo with a battery of maternal mRNAs, proteins, and mitochondria, which are related to oocyte development competence and which may contribute to apoptotic pathways but also to defense mechanisms against apoptosis (Fair et al. 1995, Otoi et al. 1997, Brevini-Gandolfi \& Gandolfi 2001, Stojkovic et al. 2001). Microinjection of healthy cytoplasm protected oxidative-stressed zygotes from apoptotic death in mice (Liu \& Keefe 2000) and improved fertility in older patients with compromised embryos in humans (Cohen et al. 1998, Barritt et al. 2001). Porcine studies have also shown that mitochondrial activity increases during meiotic progression and cumulus expansion (Thorner et al. 2004). Since the oocyte diameter increases during follicular growth (Fair et al. 1995, Hyttel et al. 2001), we may expect large oocytes to be qualitatively better because of the higher rate of mRNA, proteins, and mitochondria, and thus optimal cytoplasmic maturity which will play a role until the blastocyst stage. Nevertheless, small oocytes can also produce blastocysts, probably because the increased quality of large follicles or oocytes is thought to be 'gradual', referring to the percentage of competent oocytes and not to the higher competence of a single oocyte (Gandolfi 1998).

In conclusion, the detection of active caspase- 3 and -7 can be used as an alternative apoptotic marker during bovine embryo development. Developmental kinetics and oocyte diameter are important markers of embryo developmental potential and embryo quality in terms of the appearance of apoptosis, although the effect of oocyte diameter disappears at the blastocyst stage. Since both markers may possibly be related to cytoplasmic maturation of the oocyte in terms of maternal mRNA, proteins, and mitochondrial content, these findings indicate a significant maternal effect on embryo quality.

\section{Acknowledgements}

The authors wish to acknowledge Johanna Mestach, Griet Spaepen, and Sophie Deschryvere for their excellent technical assistance. Additionally, we are very grateful to Prof. Herman Favoreel for his advice concerning the use of the confocal laser scanning microscope. L Vandaele is a research fellow of the 'Fords voor Wetenschappelijk Onderzoek-Vlaanderen' (Belgium). The authors declare that there is no conflict of interest that would prejudice the impartiality of this scientific work.

\section{References}

Alikani M, Sadowy S \& Cohen J 2002 Human embryo morphology and developmental capacity. In Assessment of Mammalian Embryo Quality: Invasive and Non-invasive Techniques, pp 1-31. Eds A Van Soom \& ML Boerjan. Dordrecht: Kluwer's Academic Publishers.

Antczak M \& Van Blerkom J 1999 Temporal and spatial aspects of fragmentation in early human embryos: possible effects on developmental competence and association with the differential elimination of regulatory proteins from polarized domains. Human Reproduction 14 429-447.

Arlotto T, Schwartz JL, First NL \& Leibfried-Rutledge ML 1996 Aspects of follicle and oocyte stage that affect in vitro maturation and development of bovine oocytes. Theriogenology 45 943-956.

Barritt JA, Brenner CA, Malter HE \& Cohen J 2001 Mitochondria in human offspring derived from ooplasmic transplantation. Human Reproduction 16 513-516.

Bavister BD 1995 Culture of preimplantation embryos: facts and artefacts. Human Reproduction Update 1 91-148.

Brevini-Gandolfi T \& Gandolfi F 2001 The maternal legacy to the embryo: cytoplasmic components and their effects on early development. Theriogenology 55 1255-1276.

Brevini-Gandolfi T, Lonergan P, Cillo F, Favetta LA, Fair T \& Gandolfi F 2002 Evolution of mRNA polyadenylation between oocyte maturation and first embryonic cleavage in cattle and its relation with developmental competence. Molecular Reproduction and Development 63 510-517.

Brison DR \& Schultz RM 1997 Apoptosis during mouse blastocyst formation: evidence for a role for survival factors including transformating growth factor alpha. Biology of Reproduction $\mathbf{5 6}$ 1088-1096.

Byrne AT, Southgate J, Brison DR \& Leese HJ 1999 Analysis of apoptosis in the preimplantation bovine embryo using TUNEL. Journal of Reproduction and Fertility 117 97-105.

Cohen J, Scott R, Alikani M, Schimmel T, Munné S, Levron J, Wu L, Brenner C, Warner C \& Willadsen S 1998 Ooplasmic transfer in mature human oocytes. Molecular Human Reproduction 4 269-280.

Collins JA, Schandl CA, Young KK, Vesely J \& Willingham MC 1997 Major DNA fragmentation is a late event in apoptosis. Journal of Histochemistry and Cytochemistry 45 923-934.

Deveraux QL \& Reed JC 1999 IAP family proteins - suppressors of apoptosis. Genes \& Development 13 239-252.

Dinnyés A, Lonergan P, Fair T, Boland MP \& Yang X 1999 Timing of the first cleavage post-insemination affects cryosurvival of in vitroproduced bovine blastocysts. Molecular Reproduction and Development 53 318-324.

Dode MAN, Dufort I, Massicotte L \& Sirard MA 2006 Quantitative expression of candidate genes for developmental competence in bovine two-cell embryos. Molecular Reproduction and Development 73 288-297.

Earnshaw WC, Martins LM \& Kaufmann SH 1999 Mammalian caspases: structure, activation, substrates and functions during apoptosis. Annual Reviews of Biochemistry 68 383-424.

Exley GE, Tang C, McElhinny AS \& Warner CM 1999 Expression of caspase and bcl-2 apoptotic family members in mouse preimplantation embryos. Biology of Reproduction 61 231-239. 
Fair T, Hyttel P \& Greve T 1995 Bovine oocyte diameter in relation to maturational competence and transcriptional activity. Molecular Reproduction and Development 42 437-442.

Fair T, Murphy M, Rizos D, Moss C, Martin F, Boland MP \& Lonergan P 2004 Analysis of differential maternal mRNA expression in developmentally competent and incompetent bovine two-cell embryos. Molecular Reproduction and Development 67 136-144.

Favetta LA, Robert C, St. John EJ, Betts DH \& King WA 2004 P66shc, but not p53 is involved in early arrest of in vitro-produced bovine embryos. Molecular Human Reproduction 10 383-392.

Gandolfi F 1998 Embryonic development as a function of oocyte competence. In Gametes Development and Function, pp 337-353. Eds A Lauria, F Gandolfi, G Enne \& L Gianaroli. Rome: Serono Symposia.

Gjørret JO, Hiemke MK, Dieleman SJ, Avery B, Larsson LI \& MaddoxHyttel P 2003 Chronology of apoptosis in bovine embryos produced in vivo and in vitro. Biology of Reproduction 69 1193-2000.

Goyal L 2001 Direct inhibitors of caspases. Cell 104 805-808.

Grasl-Kraupp B, Ruttkay-Nedecky B, Koudelka H, Bukowska K, Bursch W \& Schulte-Hermann R 1995 In situ detection of fragmented DNA (TUNEL assay) fails to discriminate among apoptosis, necrosis and autolytic cell death: a cautionary note. Hepatology 21 1465-1468.

Grisart B, Massip A \& Dessy F 1994 Cinematographic analysis of bovine embryo development in serum-free oviduct-conditioned medium. Journal of Reproduction and Fertility 101 257-264.

Gutiérrez-Adán A, Rizos D, Fair T, Moriera PN, Pintado B, De La Fuente J, Boland MP \& Lonergan P 2004 Effect of speed of development on mRNA expression pattern in early bovine embryos cultured in vivo or in vitro. Molecular Reproduction and Development 68 441-448.

Hardy K 1999 Apoptosis in human embryo. Reviews of Reproduction 4 125-134.

Hardy K, Handyside AH \& Winston RML 1989 The human blastocyst: cell number, death and allocation during late preimplantation development in vitro. Development 107 597-604.

Hinck L, Van Der Smissen P, Heusterpreute M, Donnay I, De Hertogh R \& Pampfer S 2001 Identification of caspase-3 and caspase-activated deoxyribonuclease in rat blastocysts and their implication in the induction of chromatin degradation (but not fragmentation) by high glucose. Biology of Reproduction 64 $555-562$.

Huang J \& Dynan WS 2002 Reconstitution of the mammalian DNA double-strand break end-joining reaction reveals a requirement for an Mre11/Rad50/NSB1-containing fraction. Nucleic Acids Research 30 667-674.

Hyttel P, Viuff D, Fair T, Laurincik J, Thomsen PD, Callesen H, Vos PL, Hendriksen PJ, Dieleman SJ, Schellander K, et al. 2001 Ribosomal RNA gene expression and chromosome aberrations in bovine oocytes and preimplantation embryos. Reproduction 122 21-30.

Jurisicova A \& Acton BM 2004 Deadly decisions: the role of genes regulating programmed cell death in human preimplantation embryo development. Reproduction 128 281-291.

Jurisicova A, Varmuza S \& Casper RF 1996 Programmed cell death and human embryo fragmentation. Molecular Human Reproduction 2 93-98.

Jurisicova A, Antenos M, Varmuzza S, Tilly JL \& Casper RF 2003 Expression of apoptosis related genes during human preimplantation embryo development: potential roles for the harakir gene product and caspase- 3 in blastomere fragmentation. Molecular Human Reproduction 9 133-141.

Kanka J 2003 Gene expression and chromatin structure in the preimplantation embryo. Theriogenology 59 3-19.

Lee SM, Koh HJ, Park DC, Song BJ, Huh TL \& Park JW 2002 Cytosolic $\mathrm{NADP}(+)$-dependent isocitrate dehydrogenase status modulates oxidative damage to cells. Free Radical Biology \& Medicine 32 1185-1196.
Lequarré AS, Marchandise J, Moreau B, Massip A \& Donnay I 2003 Cell cycle duration at the time of maternal zygotic transition for in vitro produced bovine embryos: effect of oxygen tension and transcription inhibition. Biology of Reproduction 69 1707-1713.

Levy R, Benchaib M, Cordonier H, Souchier C \& Guerin JF 1998 Annexin $\mathrm{V}$ labelling and terminal transferase-mediated DNA end labelling (TUNEL) assay in human arrested embryos. Molecular Human Reproduction 4 775-783.

Li LY, Luo X \& Wang X 2001 Endonuclease G is an apoptotic Dnase when released from mitochondria. Nature 412 95-99.

Lindner GM \& Wright RW 1983 Bovine embryo morphology and evaluation. Theriogenology 20 407-416.

Liu L \& Keefe DL 2000 Cytoplasm mediates both development and oxidative-induced apoptotic cell death in mouse zygotes. Biology of Reproduction 62 1828-1834.

Lonergan P, Monaghan P, Rizos D, Boland MP \& Gordon I 1994 Effect of follicle size on bovine oocyte quality and developmental competence following maturation, fertilization, and culture. Molecular Reproduction and Development 37 48-53.

Lonergan P, Khatir H, Piumi F, Rieger D, Humblot P \& Boland MP 1999 Effect of time interval from insemination to first cleavage on the developmental characteristics, sex and pregnancy rates following transfer of bovine preimplantation embryos. Journal of Reproduction and Fertility 117 159-167.

Lonergan P, Gutierrez-Adan A, Pintado B, Fair T, Ward F, de la Fuente J \& Boland M 2000 Relationship between time of first cleavage and the expression of IGF-I growth factor, its receptor, and two housekeeping genes in bovine two-cell embryos and blastocysts produced in vitro. Molecular Reproduction and Development 57 146-152.

Maddox-Hyttel P, Gjørret JO, Vajta G, Alexopoulos NI, Lewis I, Trounson A, Viuff D, Laurincik J, Müller M \& Tveden-Nyborg P 2003 Morphological assessment of preimplantation embryo quality in cattle. Reproduction Supplement 61 103-116.

Martinez F, Rienzi L, lacobelli M, Ubaldi F, Mendoza C, Greco E \& Tesarik J 2002 Caspase activity in preimplantation human embryo is not associated with apoptosis. Human Reproduction 6 1584-1590.

Mateusen B, Van Soom A, Maes DGD, Donnay I, Duchateau L \& Lequarré AS 2005 Porcine embryo development, fragmentation and its relation to apoptotic markers: a cinematographic and confocal laser scanning microscopic study. Reproduction 129 443-452.

Matwee C, Betts DH \& King WA 2000 Apoptosis in the early bovine embryo. Zygote 8 57-68.

Metcalfe AD, Hunter HR, Bloor DJ, Lieberman BA, Picton HM, Leese HJ, Kimber SJ \& Brison DR 2004 Expression of 11 members of the BCL-2 family of apoptosis regulatory molecules during human preimplantation embryo development and fragmentation. Molecular Reproduction and Development 68 35-50.

Otoi T, Yamamoto K, Koyama N, Tachikawa S \& Suzuki T 1997 Bovine oocyte diameter in relation to developmental competence. Theriogenology 48 769-774.

Overström EW 1996 In vitro assessment of embryo viability. Theriogenology 45 3-16.

Pocar P, Brevini TA, Perazzoli F, Cillo F, Modina S \& Gandolfi F 2001 Cellular and molecular mechanisms mediating the effects of polychlorinated biphenyls on oocyte developmental competence in cattle. Molecular Reproduction and Development 60 535-541.

Rodriguez KF \& Farin CE 2004 Gene transcription and regulation of oocyte maturation. Reproduction, Fertility and Development $\mathbf{1 6}$ $55-67$.

Shi Y 2002 Mechanisms of caspase inhibition and activation during apoptosis. Molecular Cell 9 459-470.

Sjöblom C, Wikland M \& Robertson SA 2005 Granulocyte-macrophage colony-stimulating factor (GM-CSF) acts independently of the beta common subunit of the GM-CSF receptor to prevent inner cell mass apoptosis in human embryos. Endocrinology 146 2142-2153.

Spanos S, Becker DL, Winston RM \& Hardy K 2000 Anti-apoptotic action of insulin-like growth factor-I during human preimplantation embryo development. Biology of Reproduction 63 1413-1420. 
Spanos S, Rice S, Karagiannis P, Taylor DL, Becker DL, Winston RML \& Hardy K 2002 Caspase activity and expression of cell death genes during development of human preimplantation embryos. Reproduction 124 353-363.

Stojkovic M, Machado SA, Stojkovic P, Zakhartchenko V, Hutzler P, Gonçalves PB \& Wolf E 2001 Mitochondrial distribution and adenosine triphosphate content of bovine oocytes before and after in vitro maturation: correlation with morphological criteria and developmental capacity after in vitro fertilization and culture. Biology of Reproduction 64 904-909.

Thornberry NA \& Lazebnik Y 1998 Caspases: enemies within. Science 281 1312-1316.

Thorner H, Brüssow KP, Alm H, Ratky J, Pöhland R, Tuchscherer A \& Kanitz W 2004 Mitochondrial aggregation patterns and activity in porcine oocytes and apoptosis in surrounding cumulus cells depends on the stage of pre-ovulatory maturation. Theriogenology 61 1675-1689.

Vandaele L, Mateusen B, Maes D, de Kruif A \& Van Soom A 2006 Is apoptosis in bovine in vitro produced embryos related to early developmental kinetics and in vivo bull fertility? Theriogenology 65 1691-1703.

Van Soom A, Van Vlaenderen I, Mahmoudzadeh AR, Deluyker H \& de Kruif A 1992 Compaction rate of in vitro fertilized bovine embryos related to the interval from insemination to first cleavage. Theriogenology 38 905-919.

Van Soom A, Mateusen B, Maes D \& de Kruif A 2003 Fragmentation and apoptosis in bovine embryos. Theriogenology 59352.

Vigneault C, McGraw S, Massicotte L \& Sirard MA 2004 Transcription factor expression patterns in bovine in vitro-derived embryos prior to maternal-zygotic transition. Biology of Reproduction 70 1701-1709.
Ward FA, Rizos D, Corridan D, Quinn K, Boland MP \& Lonergan P 2001 Paternal influence on the time of the first embryonic cleavage post insemination and the implications for subsequent bovine embryo development in vitro and fertility in vivo. Molecular Reproduction and Development 60 47-55.

Wells D, Bermudez MG, Steuerwald N, Malter HE, Thornhill AR \& Cohen J 2005 Association of abnormal morphology and altered gene expression in human preimplantation embryos. Fertility and Sterility 84 343-355.

Yoshioka K, Suzuki C \& Iwamura S 2000 Effects of activin A and follistatin on developmental kinetics of bovine embryos: cinematographic analysis in a chemically defined medium. Journal of Reproduction and Fertility 188 119-125.

Yuan YQ, Peelman LJ, Williams JL, Van Zeveren A, de Kruif A, Law A \& Van Soom A 2004 Mapping and transcription profiling of CASP1, 3, 6,7 and 8 in relation to caspase activity in the bovine cumulusoocyte complex. Animal Genetics 35 234-237.

Yuan YQ, Van Soom A, Leroy JLMR, Dewulf J, Van Zeveren A, de Kruif A \& Peelman LJ 2005 Developmental competence of bovine oocytes may be influenced by apoptosis in compact cumulus cells but is unrelated to oocyte programmed cell death. Theriogenology $632147-2163$.

Received 17 July 2006

First decision 29 August 2006

Revised manuscript received 11 January 2007

Accepted 15 January 2007 